\title{
Social Construction of Light and Dark Dimensions of Leadership: Exploring the Origins of Destructive Leadership
}

\author{
Gail F. Latta \\ Xavier University \\ Ashley L. Whitely \\ Wyoming City Schools
}

This industry-wide ethnography explores leader emergence and accountability by analyzing the light and dark dimensions of attributes exhibited by individuals selected for leadership roles. Social identity theory provided a lens for exploring how organizational culture shapes both what attributes are prototypical, and which light and dark dimensions were reflected among the leaders in three companies representative of the industry. Results reveal these leaders were not uniquely skilled at navigating between the light and dark extremes of prototypical attributes, and were no more likely to embody light dimensions, or moderate the expression of dark dimensions. Implications for destructive leadership are discussed.

Keywords: Leadership Theory, Light and Dark Trait Dimensions, Social Identity Theory, Ethnography, Ballet Industry, Organizational Culture

\section{INTRODUCTION}

The study of personal attributes that predict leader emergence and effectiveness has enjoyed a $21^{\text {st }}$ century renaissance in the field of leadership due to both conceptual and methodological innovations (Judge Piccolo \& Kosalka, 2009; Zaccaro, 2007). This revival of trait-based theories of leadership is predicated on recognizing the dimensionality of individual attributes of character. These theories assert both positive and negative attributes predict leader emergence and effectiveness, but only at optimal levels. Possessing too much of a positive attribute such as charisma or conscientiousness can contribute to diminished leader effectiveness (Benson and Campbell, 2007), whereas possessing a modicum of a negative attribute such as narcissism, may be associated with leadership success (Furnham, Hyde \& Trickey, 2014). Character attributes manifest as "light" or "dark" depending upon their favorable or unfavorable effects in organizations, with optimal levels of attribute dimensionality promoting leader emergence and effectiveness (Judge et al., 2009). Recognition that these curvilinear relationships predict effective leadership has added nuance to the study of individual differences among leaders in organizations and enhanced understanding of the contextual nature of leadership.

The moderating effects of situational factors such as organizational culture on the expression of individual attributes that impact leader emergence, advancement and effectiveness are highlighted in contemporary trait theories of leadership (Judge et al., 2009; Zaccaro, 2007). By implication the 
individual attributes that predict leader effectiveness are not universal, but specific to particular organizational contexts (Zaccaro, Kemp \& Bader, 2004). According to social identity theory (Hogg, 2001), the manifestation of these attributes is socially determined, shaped by a cultural environment that dictates which attributes are considered prototypical, and what dimensions of those attributes are considered positive ("light") and negative ("dark") (Judge et al., 2009). Taken together, these theories predict individuals who reflect prototypical attribute dimensionality will tend to be promoted to leadership positions, while those lacking these manifest attributes are either selected out of the organization or are not promoted.

These recent theoretical developments raise empirical questions about the effects of attribute dimensionality on leader emergence and effectiveness in specific organizational contexts. How do elements of organizational culture determine what attributes are considered prototypical, and which "light" and "dark" dimensions are manifest by individuals elevated to leadership roles in particular organizations? Do individuals in leadership positions reflect all or some prototypical attributes? Do these emergent leaders reflect the extremes of dimensionality or moderate the expression of these 'light' and dark' dimensions? Do the cultural dynamics that shape leadership emergence and effectiveness in organizations pervade an entire industry?

\section{RESEARCH QUESTIONS}

A multi-organizational ethnographic study was conducted to address these theoretical questions by documenting the light and dark dimensions of culturally determined prototypical attributes of leader emergence and effectiveness in the American ballet industry (ABI). The ballet industry was selected for this study because it is often portrayed in the media as valuing aesthetic extremes (Kelly, 2012), thereby maximizing the potential to discern the effects of organizational culture on leader prototypically. Ethnographic epistemologies were employed to explore how organizational culture shapes what leadership attributes are prototypical, and the extent to which light and dark dimensions of these attributes are reflected among leaders in the ballet industry.

The overarching research question addressed was: How does the culture of the ABI shape the light and dark dimensionality of prototypical attributes manifest among members selected for leadership roles in the industry?"

Specific sub-questions focused analysis and interpretation of results:

RQ1. What prototypical attributes are reflected in the culture of the American ballet industry?

RQ2. What light and dark dimensions of prototypical attributes are reflected among individuals selected for leadership roles in the American ballet industry?

RQ3. To what extent do leaders in the American ballet industry reflect both the "light" and "dark" dimensions of prototypical leadership attributes?

RQ4. Are individuals elevated to leadership positions atypical of others in the ballet industry with respect to reflecting more "light" than "dark" dimensions of prototypical attributes?

\section{THEORETICAL FRAMEWORK}

The study of leader attributes that predict emergence and effectiveness has evolved to encompass both genetically determined traits (Judge et at., 2009) and those "relatively stable and coherent integrations of personal characteristics that foster a consistent pattern of leadership performance across a variety of group and organizational situations... reflect[ing] a range of individual differences, including personality, temperament, motives, cognitive abilities, skills and expertise" (Zaccaro et al., 2004, p. 104). "Light" and "dark" manifestations of these attributes (attribute dimensionality) affect whether they predict 
leader emergence and effectiveness (Judge et al., 2009). Theoretically, attribute manifestations, including dimensionality, are subject to moderation by elements of the leader's operating environment, including organizational culture (Zaccaro, 2007). Thus, dynamics of leader emergence are governed in large part by social identity theory (Hogg, 2001), which asserts individuals elevated to leadership positions are those who embody the most prototypical attributes reflected in the culture of an organization. Therefore leader prototypically and dimensionality are both determined by organizational culture (Hogg, 2001), which in turn dictate leader emergence (Zaccaro et al., 2004) (see Figure 1).

\section{FIGURE 1 \\ THEORETICAL FRAMEWORK INTEGRATING ZACCARO'S (2007) TRAIT-BASED LEADERSHIP MODEL WITH HOGG'S (2001) SOCIAL IDENTITY THEORY}

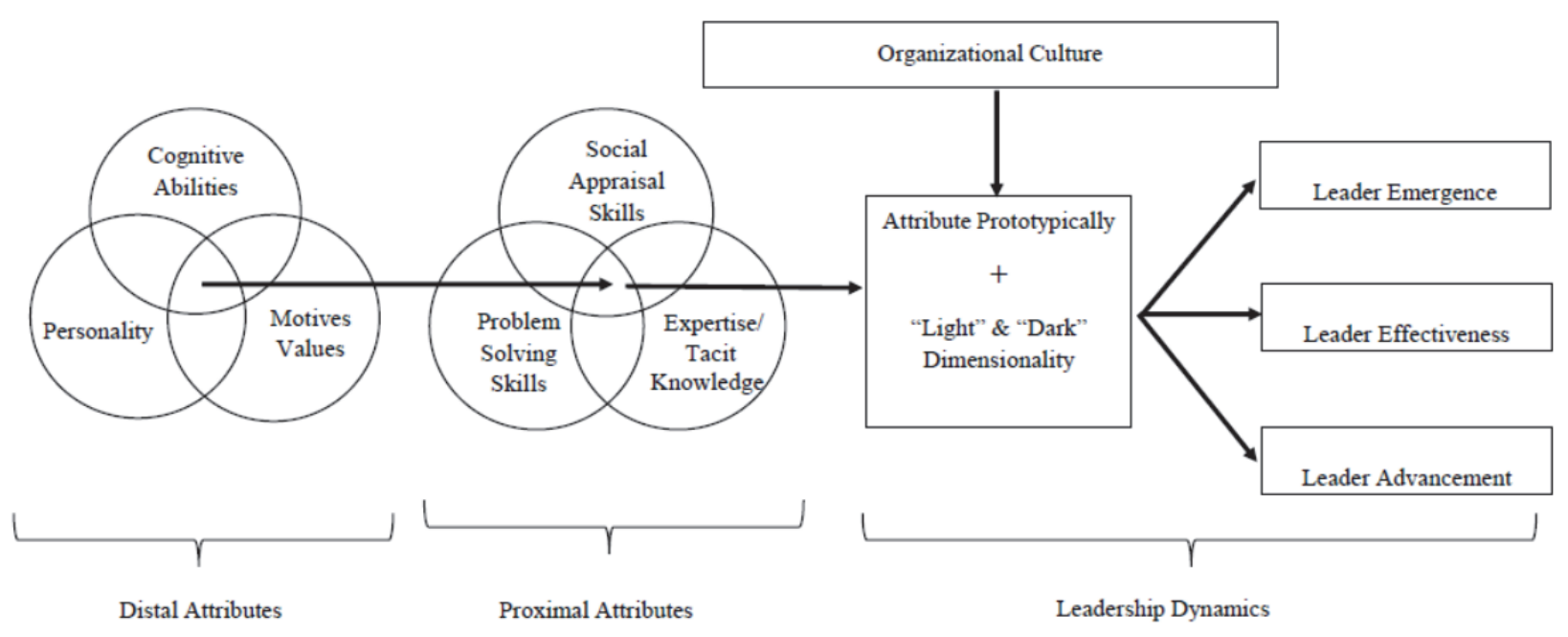

\section{Leader Attribute Dimensionality}

The recognition that diminished leader effectiveness might be associated with individual characteristics gave rise to the codification of "light" (or "bright") and "dark" leadership attributes. Initially, Hogan and Hogan (2001) differentiate 11 negative attributes that parallel personality dysfunctions defined by the Diagnostic and Statistical Manual of Mental Disorders (DSM-IV) (American Psychiatric Association, 1994), which they predicted would precipitate leader derailment (Hogan, 2016). Subsequently, some of these "dark" attributes were shown to contribute, in some instances, to positive leadership outcomes: Khoo and Burch (2008) found positive correlations between transformational leadership and two "dark" attributes on the Hogan scale, "colorful" (histrionic) and "mischievous" (antisocial); Harms, Spain \& Hannah (2011) revealed positive implications of "dark" attributes in a longitudinal study of military cadets; and Zibarras, Prot \& Woods (2008) reported two "dark" attributes, narcissism and anti-social behavior, were associated with managerial innovation. Simonet, Tett, Foster, Angelback \& Bartlett (2018) reported positive interactions between two or more "dark" attributes.

More recent efforts to determine the effect of trait dimensionality on leadership conceptualize "dark" attributes as extreme amounts of otherwise "light" attributes such as the Big Five personality factors (McCrae and Costa, 1987). Judge et al. (2009) argue "modest levels of a bright trait are attractive, desirable, and functional for leadership and group effectiveness, but extreme cases...threaten the stability and survival of a particular group" (p. 864) and are therefore considered "dark". These theorists assert any attribute could simultaneously manifest both "light" and "dark" dimensions, depending upon it prototypically, with dark dimensions representing negative manifestations of attributes typically considered socially desirable, and "light" dimensions being positive manifestations of attributes ordinarily considered undesirable. Kaiser, LeBreton \& Hogan (2015) found support for hypotheses predicting negative behavioral consequences of possessing either "too much" or "too little" of a number of positive 
leadership attributes. Extraversion and conscientiousness are examples of socially desirable leader attributes that can sometimes have "dark" (negative) implications for leader effectiveness (Hogan and Hogan, 2001), while narcissism, a socially undesirable attribute, has a "light" (positive) manifestation that correlates with leader emergence and effectiveness (Furnham and Crump, 2014).

\section{Cultural Basis for Attribute Prototypically}

In addition to accounting for the nuances of dimensionality, contemporary trait theories of leadership also recognize the moderating effects of situational factors such as organizational culture on leader emergence and effectiveness (Judge et al., 2009; Zaccaro et al., 2004). Previous studies of light and dark dimensions of leadership attributes have been carried out without regard for organizational context (Hogan and Hogan, 2001; Kaiser et al., 2015; Khoo and Burch, 2008), though Simonet et al. (2018) reported cross-situational effects and suggested organizational culture "warrants attention as a [potential] situational moderator" (p. 245) in future research. According to social identity theory (SIT) cultural context dictates what attributes are considered desirable, i.e. prototypical, among individuals selected for leadership roles in particular organizations (Hogg, 2001). As Judge et al. (2009) describe, cultural context determines the "paradoxical utility" of leader attributes:

Many socially desirable personality traits (i.e., "bright": those viewed positively by most individuals in society) are likely to be valuable for leader emergence and leadership effectiveness in many if not most circumstances. Yet these same traits could be counterproductive in particular contexts or with followers who do not regard these narrow traits as favorable for group survival. (p. 864).

\section{METHODOLOGY}

Using qualitative methods, this study explores the extent to which organizational culture determines both the prototypicality of leadership attributes, and the manifestation of "light" and "dark" dimensions of these attributes among organization members, particularly those selected for leadership roles. To the extent all members of an organization are socially selected and enculturated (Louis, 1990), the tacit strictures of organizational culture shape the expression of desired attributes, and their light and dark manifestations, particularly among those who will eventually emerge as leaders based upon their prototypically (Hogg, 2001). Informed by these assumptions, this study examines how the culture of the American ballet industry both dictates what attributes are prototypical of its members, and determines the light and dark attribute dimensionalities manifest among individuals who emerge as leaders in these organizations.

The ABI represents a relatively insular institutional environment that embodies normative assumptions and cultural ideals that are atypical of the non-initiated population, and where acculturation typically begins at an early age (Kelly, 2012). Rather than imposing a normative assessment of light and dark dimensions of leadership, we adopted an ethnographic approach, using unobtrusive observation and semi-structured, reflexive interviews, to permit exploration of the full range of leader attributes valued by members of the ABI (Alasuutari, 1995; Fetterman, 1998). Open coding was used to extract leadership attributes and dimensionality, from interview transcripts and field notes, rather than imposing a preexisting taxonomy of leader attributes on the data (Holton, 2007). These methodological decisions were adopted to avoid constraining results by imposing arbitrary assumptions about leadership during data analysis.

\section{Data Collection}

An ethnographic approach to data collection was employed using non-participant observation and semi-structured interviews (Driskell and Brenton, 2011). Cultural analysis focused on the meaning embedded in the many visual artifacts, verbal and physical patterns of behavior, normative practices, interpersonal mannerisms, and artifacts documented (Schultz, 1995). To capture an industry-wide 
perspective, data were collected from three professional ballet companies in different regions of the United States: Rocky Mountain, Midwestern, and Pacific Northwest between December 2016 and March 2017. Because the focus of study was on understanding how organizational culture shapes prototypically for all members of an organization, the scope of ethnographic analysis was not limited to those in leadership roles. Within each company, stratified participant recruitment was used to ensure broad representation across all roles and ranks, levels of involvement, leadership positions, and length of tenure. Observations and interviews were arranged with dancers, directors, choreographers, support and administrative staff. Both those on the stage and behind the scenes were interviewed, since understanding the interplay of subgroups in the ballet companies was essential to constructing a complete ethnographic representation of ballet culture. Observations occurred in a wide range of settings: practices, rehearsals, meetings, trainings, and performances. Field notes were taken to capture a broad array of cultural forms (e.g. artifacts, norms, language, symbols).

As a non-participant observer, the researcher's presence was known and visible to members of the organization, although no direct interaction or participation took place during observed activities, and interviews were arranged via email to occur outside of regularly scheduled events and contexts (Dane, 1990). Key informants emerged or were recruited in each ballet organization. These individuals participated in follow-up interviews in which they provided more detailed information and insight into the behaviors and cultural dynamics in their organization. Reflexive questioning during interviewing aided researchers' understanding of observed events and allowed opportunities for probative inquiry regarding an emic (insider's) interpretation of cultural artifacts (Fetterman, 1998). Deliberative sampling reflecting the demographics of the organization utilizing the ballet companies' rosters continued until data saturation was achieved. Both institutional and individual informed consent were obtained prior to data collection. A total of 75 semi-structured interviews were conducted, almost evenly split between males (40) and females (35). Although the percent of males interviewed was slightly greater overall, ratios reflected the gender distribution in each organization and role. A breakdown of interview participants stratified by role in each company, with combined totals across all organizations, is presented in Table 1.

TABLE 1

\section{OVERALL AND STRATIFIED BREAKDOWN OF INTERVIEW PARTICIPANTS BY ORGANIZATIONAL ROLE \& BALLET COMPANY}

\begin{tabular}{ccccc}
\hline $\begin{array}{c}\text { Companies } \\
\text { Role }\end{array}$ & $\begin{array}{c}\text { Rocky Mountain } \\
\text { n of N/ } \%\end{array}$ & $\begin{array}{c}\text { Mid-Western } \\
\text { n of N/ } \%\end{array}$ & $\begin{array}{c}\text { Pacific Northwestern } \\
\text { n of N/ } \%\end{array}$ & $\begin{array}{c}\text { Total All } \\
\text { n of N/ } \%\end{array}$ \\
\hline Core Dancers & 6 of $18 / 33 \%$ & 15 of $19 / 78 \%$ & 9 of $12 / 75 \%$ & 30 of $49 / 61 \%$ \\
Principal Dancers & 8 of $22 / 36 \%$ & $\mathrm{n} / \mathrm{a} * \mathrm{n} / \mathrm{a}$ & 2 of $4 / 50 \%$ & 10 of $26 / 38 \%$ \\
Total Dancers & 14 of $40 / 35 \%$ & 15 of $19 / 78 \%$ & 11 of $16 / 69 \%$ & 40 of $75 / 53 \%$ \\
Artistic Admin. & 3 of $6 / 50 \%$ & 3 of $3 / 100 \%$ & 2 of $2 / 100 \%$ & 11 of $8 / 73 \%$ \\
Executive Admin. & 10 of $27 / 37 \%$ & 6 of $7 / 85 \%$ & 4 of $5 / 80 \%$ & 20 of $39 / 51 \%$ \\
Total Admin. & 13 of $33 / 39 \%$ & 9 of $10 / 90 \%$ & 6 of $7 / 86 \%$ & 28 of $50 / 56 \%$ \\
Production & 3 of $12 / 25 \%$ & 4 of $4 / 100 \%$ & 0 of $1 / 0 \%$ & 7 of $17 / 41 \%$ \\
Total all Roles & 30 of $85 / 35 \%$ & 28 of $33 / 85 \%$ & 17 of $24 / 71 \%$ & 75 of $142 / 53 \%$ \\
\hline
\end{tabular}

*the roles Principle \& Solo Dancers did not exist in the Mid-Western ballet company

\section{Data Analysis}

Data analysis involved triangulation of evidence to ensure credibility, confirmability, and dependability of results (Whitley and Kite, 2013). Both field notes and interview transcripts were coded and interpreted in a two-step process, using an inquiry audit of preliminary results to confirm initial coding. Member checking was employed to ensure accuracy in recording and interpreting narrative testimony. 


\section{RESULTS}

Initial interpretation of results focused on addressing the first two research questions informing this ethnographic study: Identifying the prototypical attributes reflected in the culture of the ABI, and the light and dark dimensions of these attributes manifest among individuals occupying leadership roles. A total of 14 discrete prototypical attributes embodied by members of the ABI were extracted from this ethnographic analysis. A clear and distinct conceptual definition for each prototypical attribute emerged from data analysis. All 14 attributes were found to manifest both "light" and "dark" dimensions in the cultural context of the ballet industry. Tables summarizing these results delineate the dimensionality of each culturally-determined prototypical attribute, with examples illustrating the "light" and "dark" manifestations of each (see Tables $2 \& 3$, respectively). The resulting thick text analysis of findings presented below reflects evidence consolidated across all participating ballet companies.

\section{TABLE 2}

\section{LIGHT DIMENSIONS OF PROTOTYPICAL ATTRIBUTES MANIFEST IN BALLET CULTURE WITH EXAMPLES}

\begin{tabular}{|c|c|c|}
\hline Attributes & Light Dimensions & Examples in Ballet Culture \\
\hline Flexibility & $\begin{array}{l}\text { adaptability, compromise, } \\
\text { cooperation, versatility }\end{array}$ & $\begin{array}{l}\text { dancers' ability to perform movements with their } \\
\text { body \& to learn concurrent routines }\end{array}$ \\
\hline Perfectionism & $\begin{array}{l}\text { ideals/standards of beauty } \\
\text { high expectations/goals }\end{array}$ & $\begin{array}{l}\text { quality performance/production; languid/precise } \\
\text { movements of dancers; projecting opulence }\end{array}$ \\
\hline Independence & $\begin{array}{l}\text { self-confidence, } \\
\text { resourcefulness }\end{array}$ & $\begin{array}{l}\text { one-person departments require high expertise } \\
\text { taking personal responsibility for self \& career }\end{array}$ \\
\hline Artistry & $\begin{array}{l}\text { aesthetics, glamour, } \\
\text { composure, emotion }\end{array}$ & $\begin{array}{l}\text { expectation of quality for dancers movements; } \\
\text { capture/sell emotion/aesthetics of ballet }\end{array}$ \\
\hline Intelligence & $\begin{array}{l}\text { Accomplishment, } \\
\text { creativity }\end{array}$ & $\begin{array}{l}\text { ability to secure sponsors, oversee budget; ability to } \\
\text { assemble pieces of a production }\end{array}$ \\
\hline Dedication & $\begin{array}{l}\text { commitment, resolve, } \\
\text { zeal }\end{array}$ & $\begin{array}{l}\text { artistic directors' commitment to sewing costumes } \\
\text { or making headpieces }\end{array}$ \\
\hline Communication & $\begin{array}{l}\text { expression, efficiency, } \\
\text { dialogue, teamwork }\end{array}$ & $\begin{array}{l}\text { pas de deux (partnering of dancers), ballet's } \\
\text { capacity to move audiences to tears }\end{array}$ \\
\hline Attention to detail & $\begin{array}{l}\text { high expectations, } \\
\text { polished outcomes }\end{array}$ & $\begin{array}{l}\text { elaborately orchestrated fundraising events, } \\
\text { costumes and set production }\end{array}$ \\
\hline Individuality & $\begin{array}{l}\text { uniqueness, balanced } \\
\text { teamwork }\end{array}$ & $\begin{array}{l}\text { dancers' capacity to command stage; artistic } \\
\text { directors' ability to conceive novel performances }\end{array}$ \\
\hline Longevity & $\begin{array}{l}\text { loyalty, traditions, } \\
\text { historical knowledge }\end{array}$ & $\begin{array}{l}\text { dancers turnover; retention of founding member } \\
\text { promoted to artistic directors; minimal }\end{array}$ \\
\hline Appreciation & adoration, love, beauty & $\begin{array}{l}\text { love of the art and an enduring adoration for the } \\
\text { ideals it embodies }\end{array}$ \\
\hline Competition & $\begin{array}{l}\text { teamwork, production, } \\
\text { motivation, creativity }\end{array}$ & $\begin{array}{l}\text { all departments work together to create highest } \\
\text { quality production }\end{array}$ \\
\hline Fearlessness & $\begin{array}{l}\text { creativity, decisiveness, } \\
\text { exceeding boundaries }\end{array}$ & $\begin{array}{l}\text { dancers' master difficult choreography; artistic } \\
\text { directors forge ahead despite limited resources }\end{array}$ \\
\hline Confidence & $\begin{array}{l}\text { command, strength, } \\
\text { strong "voice" }\end{array}$ & $\begin{array}{l}\text { dancers commanding a stage so all eyes on them; } \\
\text { artistic staff leading a rehearsal }\end{array}$ \\
\hline
\end{tabular}

\section{Cultural Profile of the American Ballet Industry}

The composite cultural profile that emerged from observations of daily routines across three ABI companies revealed a high degree of industry uniformity. Examples of cultural integration, differentiation and fragmentation were all evident (Martin, 2002). The following profile, annotated with anonymous 
quotes from participants, details the dimensionality of emergent elements of culture that shape leader emergence and effectiveness in this organizational context.

\section{An Unattainable Ideal}

The essence of ballet culture is an unadulterated commitment to perfectionism, in pursuit of an unattainable ideal of beauty, elegance and effortlessness. Commitment to this impossible ideal creates an intense drive for perfection that is considered the industry standard: "what is ballet if not a little unrealistic, a little unattainable?" (EC9). The drive to achieve this unattainable ideal shapes every aspect of ballet culture. Dancers symbolize the unrealistic ideals of beauty and elegance, and feel pressured to defy the laws of human nature in pursuit of those artistic standards: "we aren't human; we are dancers" (GD4). Yet the expectation to appear as "unattainable creatures who work on a lighter plane" (UA1) becomes demoralizing when dancers are told, "You did that perfect. Now do it better" (UC2). This culture of unattainable ideals can also conflict with the practicalities of running a business that depends on achieving a sublime artistic vision with inadequate fiscal and human resources.

TABLE 3

\section{DARK DIMENSIONS OF PROTOTYPICAL ATTRIBUTES MANIFEST IN BALLET CULTURE WITH EXAMPLES}

\begin{tabular}{|c|c|c|}
\hline Attributes & Dark Dimensions & Examples in Ballet Culture \\
\hline Flexibility & $\begin{array}{l}\text { limitless, confusion, } \\
\text { fluctuation }\end{array}$ & $\begin{array}{l}\text { continual modifications to choreography confusing } \\
\text { dancers/staff; manipulating revenues and expenditures }\end{array}$ \\
\hline Perfectionism & $\begin{array}{l}\text { unattainable vision, } \\
\text { entitlement, unhealthy } \\
\text { unreasonableness }\end{array}$ & $\begin{array}{l}\text { extreme obsession with ideal body image, e.g. juice } \\
\text { diets; dancing through injury for fear of looking weak } \\
\text { or loosing position or standing }\end{array}$ \\
\hline Independence & $\begin{array}{l}\text { disconnectedness, } \\
\text { complacency, factions } \\
\text { divisiveness }\end{array}$ & $\begin{array}{l}\text { organizational silos, dancers, artistic an executive } \\
\text { personnel operating as three separate entities with } \\
\text { limited integration or coordination }\end{array}$ \\
\hline Artistry & facade, distraction & hiding injury; stretching budget too thin \\
\hline Intelligence & $\begin{array}{l}\text { rationalization, } \\
\text { justification, }\end{array}$ & $\begin{array}{l}\text { transforming mirrors into instruments of torture; } \\
\text { excusing cost overruns; rationalizing unhealthy weight }\end{array}$ \\
\hline Dedication & $\begin{array}{l}\text { consumption, } \\
\text { preoccupation }\end{array}$ & $\begin{array}{l}\text { over-performing to the point of exhaustion; excessively } \\
\text { long hours for all in the industry }\end{array}$ \\
\hline Communication & directive, obedience & $\begin{array}{l}\text { constant negative critique from artistic staff; dancers } \\
\text { being seen but not heard during rehearsals }\end{array}$ \\
\hline Attention to detail & $\begin{array}{l}\text { obsession, tedium } \\
\text { micro-managing }\end{array}$ & $\begin{array}{l}\text { over-reaction or excessive rebuke for incidental events } \\
\text { (fallen headpiece/prop, brushing curtain exiting stage) }\end{array}$ \\
\hline Individuality & $\begin{array}{l}\text { selfishness, lack of } \\
\text { empathy, antagonism, } \\
\text { self-absorption }\end{array}$ & $\begin{array}{l}\text { getting ahead at others' expense; taking advantage of } \\
\text { others' misfortune or injury; need to stand out at all } \\
\text { cost; lack of departmental collaboration }\end{array}$ \\
\hline Longevity & $\begin{array}{l}\text { complacency, } \\
\text { resignation, settling }\end{array}$ & $\begin{array}{l}\text { belief that the ideal is the "normal"; executive } \\
\text { administrators' view that good is good enough }\end{array}$ \\
\hline Appreciation & $\begin{array}{l}\text { skewed reality, biased } \\
\text { perception, blind spots }\end{array}$ & $\begin{array}{l}\text { skirting ethics to produce a flawless production (e.g. } \\
\text { costume sales) }\end{array}$ \\
\hline Competition & $\begin{array}{l}\text { aggression, hostility } \\
\text { sabotage }\end{array}$ & $\begin{array}{l}\text { every dancer vying for same roles/spots; questioning } \\
\text { the authenticity of a peer's assistance }\end{array}$ \\
\hline Fearlessness & riskiness, recklessness & $\begin{array}{l}\text { unhealthy body image; eating disorders; dancing thru } \\
\text { injury; inaccurate budget projections causing deficits }\end{array}$ \\
\hline Confidence & $\begin{array}{l}\text { arrogance, narcissism, } \\
\text { egotism, hubris }\end{array}$ & $\begin{array}{l}\text { bullying dancers through feedback/critique; artistic and } \\
\text { executive staff insisting their way is the only way }\end{array}$ \\
\hline
\end{tabular}




\section{Dimensionality of Prototypical Leadership Attributes in Ballet Culture}

As Kelly (2012) observed, "from the beginning, the image of the ballerina has been cast in contrasting ways. This is the source of her duality" (p. 2). Our analysis explores that duality as it relates to the dimensionality of attributes characteristic of members of the ABI and individuals who emerge as leaders in the ballet industry.

\section{Flexibility}

Flexibility captures the very essence of the dancer's languid movements that mesmerize audiences. Because all individuals including dancers have limitations, flexibility is valued among members of the ballet industry. Dancers selected for leadership positions exhibit awe-inspiring physical flexibility, as well as the mental agility to memorize numerous performances, roles, and their corresponding steps. Role flexible is necessary when called upon to substitute for other dancers, sometimes at a moment's notice. All these forms of versatility are required because "you have to be able to handle anything thrown at you" (EC1). Dancers can no longer simply rely upon classical technique: they have to be pliable, literally and figuratively, to learn more contemporary styles. As one artistic director noted, a dancer's need for flexibility essentially requires him or her to be "a chameleon" (UA1).

Flexibility or adaptability, both mental and physical, are considered essential for leaders in the ballet industry. The light aspects of this attribute allow leaders to morph and adapt to situations. Ballet organizations demonstrate flexibility through continuous revision of their artistry and choreography, and the ballet industry has remained relevant through the years by constantly reinventing itself (GA2); its current status as an elite art form is far from the scandal, sex, and suffering of its early origins (Kelly, 2012). Flexibility among ballet leaders enables artistic staff to reconfigure steps as necessary to adjust for unanticipated factors, adapt for greater ease, or accommodate dancers who simply cannot perform as desired. Musical directors, too, must adapt scores and adjust tempos to satisfy the vision of artistic staff. Company finances often require leaders to be flexible, as when an executive overestimates ticket sales for a performance.

Yet, flexibility has a dark dimension that manifests when leaders fail to realize and respect that people and organizations have limits. Just as dancers struggle to accept the range of motion that constrains the human body, artistic directors sometime fail to respect the limits of a dancer's mind to absorb countless revisions to choreography, resulting in confusion: "We have a tendency in dance to manage by 'I don't know what it is, but I will know it when I see it.' We cannot give people direction, so we make correction after correction" (GE1). Artistic directors and production staff must adapt to the ebb and flow of finances, adjusting their ideas to available resources. For some leaders, that adaptability means paying for elements of production out of pocket, rather than sacrificing the ideal (GA1). Similarly, executives who pride themselves on stretching limited budgets are sometime unwilling to engage in difficult conversations about how deficits impact programming and require production changes. Constant malleability means people "don't know the target" (GD5), ensuring it will not be met.

\section{Perfectionism}

Consistent with the idealism inherent to the culture of the ballet industry, perfectionism is another attribute valued among its members. A "commitment to excellence" (UA1), and the ability to help others achieve it, are considered necessary for someone to emerge as a leader in the ballet industry. Perfectionism among their leaders allows ballet companies to strive for lofty goals and maintain standards that enhance reputation. Leaders who exhibit and express a yearning for perfection strive to realize the ideal they envision, whether a precise dance move, a flawless performance, or robust ticket sales. Production staff seek technical perfection in hanging costumes on hangers and storing props properly. Repetition is the means of achieving perfection in ballet culture, where the goal is to produce movements that look effortless and flawless from head to toe. As with the dancers, leaders throughout the ballet industry from artistic directors and costume designers to wardrobe and set designers, reflect this commitment to anticipating and preventing any imperfection from marring a production. As one artistic 
director explained, "Good is the demise of great", (GA1); while a development officer confessed "Largely elements are out of my hand, but I feel responsible. "I want to be perfect" (EE2).

While the light side of perfectionism serves to sustain the pursuit of a beautiful ideal, the dark underbelly is that, "it can take over your whole life" (GD11) and create a skewed perception of reality. For a dancer, that skewed perception can precipitate a disregard for health in pursuit of an unattainable body image, and a disrespect for injury that can threaten a career. That same perfectionism can induce executive staff to make unreasonable projections for ticket sales (GP4), and artistic staff to overreact to minor imperfections in a performance. A brush of the curtain coming off stage, a headpiece that accidentally drops, an arm placement that is slightly off may assume disproportional importance: "They begin to take everything too seriously: they cannot distance self from self" because they are so caught up in the idea of perfection in a performance (GP1). Collectively, the dark aspects of perfectionism create divisiveness among administrative leadership, with each stubbornly committed to their respective skewed versions of reality.

\section{Independence}

Dancers' independence is on display when they practice alone in a studio to perfect their movements, watch video of past choreography to understand the nuances they must bring to the stage, or ask other dancers to model movements they need to master. Leaders in the ballet industry are also independent, taking initiative rather than waiting for direction. Both artistic and executive administrators thrive on independence, acting to ensure work gets done: These "leaders really help people become more independent, to become more critical of themselves for this is how the outcome can actually be reached" (EE3). As lean organizations, ballet companies depend on the light dimension of independence to enable individuals to "carry their own weight," "give whatever it takes," and "make it happen." That independence permits principal dancers to command a stage, artistic directors to commit to a vision, and financial officers to secure obscure sources of funding.

But an overreliance on independence among leaders in the ballet industry can have a dark side, creating silos that result in separation, isolation, disconnectedness and an 'us vs. them' mentality. Divisions between dancers, artistic staff and executive administrators are deeply engrained in ballet culture, each attempting to solve their problems in isolation. Dancers, who receive constant feedback, rarely seek help fixing their mistakes, and question the motives of anyone who offers assistance, viewing them as 'competitors'. Principal dancers commonly lament, "It is lonely at the top". Artistic staff become blind to the contributions others could make to their vision, while executive staff resent never being brought into the conversation. One dancer who recognized the dangers of excessive independence observed, "You can't have a separateness or a divisive quality" (GD3); few ballet leaders shared this insight.

\section{Artistry}

Artistry manifests in every aspect of ballet culture. It is the essence of the ideal projected by the industry; without it, ballet would cease to exist. Artistry is an attribute observed among leaders who thrive in the ballet industry that "can be learned, but not taught" (UA1). Through their artistry, dance leaders stand out from the proverbial crowd by perfecting their flawless movements. Artistic leaders captivate and amaze audiences with their repertoire of choreography, stage craft, and productions. Directors display artistry through their coordination of elaborately themed fundraising events, complete with food spreads, props and displays of historical artifacts that pay homage to old traditions and new perspectives. One astute marketing executive noted, "You will move quicker if you can embrace the artistry," (GE2). Artistry is where ballet leaders' creativity flourishes, in a microcosm that attests "life is a show" (GE1).

Yet the artistry of ballet culture conceals a darkness: it can become a facade that obscures truth and breeds inauthenticity and denial. Behind the beauty dancers project, they may be battling a dysmorphic view of self. Their "glamour" (UA1) may be covering up eating disorders, injury, and self-loathing. For executive administration their elaborate fund raising events may represent "window dressing" that belies dancers' meager salaries, under-budgeted productions and cost overruns. Production uses artistry to make 
sets look extravagant and costumes pristine when in reality "Band-Aids and duct tape are holding them together" (UA1). This lack of authenticity is the darkness lurking beneath the lighter side of artistry in ballet culture.

\section{Intelligence}

Intelligence is indisputably essential to the ballet industry because it enables leaders' ideals to become reality. Intelligence undergirds the leadership culture of the ballet industry: Dancers must be quicklearners and make informed decisions about their bodies, regarding both image and injury. Artistic staff must be savvy in converting aesthetic ideals into reality, requiring minds that can assemble an integrated whole from myriad intricate parts, seeing where each part fits. The intelligence of executive staff is evident in their good judgment about procuring and allocating scarce resources. As one executive director noted, "if you push button A twelve times and B pops up, and you don't want B, you have to stop pushing button A. You have to stop being an idiot and do something different" (UE10). Ultimately ballet works because of the combined efforts of individuals who contribute their acumen, intelligence, and expertise.

Unfortunately the dark shadow side of intelligence, rationalization, is seldom acknowledged: everyone in the ballet community is smart enough to rationalize their dangerous behaviors. A dancer convinces herself that dancing while injured is best for the company and her career, or that losing just a few more pounds will achieve her ideal body image. Rather than adjust the choreography to match dancers' abilities, artistic staff rationalize more rehearsals will make everything better. Executive and production staff advocate expanding the company despite knowing the resources are not there to do so. In the ballet world leaders' intelligence can serve as a basis for rationalizing, rather than facing problems.

\section{Dedication/Loyalty}

Dedication to the industry is a hallmark of ballet culture valued among its leadership. Since "this job is sacrifice" (UP1), dedication is required to endure the toll it takes on a dancer's body. When toes are bleeding, and a person can barely walk, it takes a combination of tenacity and perseverance to muster the dedication to put a foot into a toe shoe. Dedication sustains a dancer after countless hours of practice, or when overlooked for a role, yet must still dance in the performance, supporting the dancer who scored the desired part. Artistic staff dedicate themselves to bringing an aesthetic vision to fruition, and everyone is committed to staging as many performances as feasible, so they can share their craft with others. Many executive administrators who come to ballet from outside the industry demonstrate their dedication by taking adult ballet classes, to enhance their understanding and appreciation for the art form and its challenges. In a profession where 30 is considered old, salaries are meager, and retirement plans are nonexistent, dedication is the only possible explanation for persistence. As one marketing director stated, "You have to be dedicated to the art to have an ability to work and accomplish within the chaos. It can be beautiful fun" (GE2). This level of dedication explains why for most ballet leaders, "this is their life, not their work" (EE3).

Dedication is prized in the ballet industry, and its light aspects fuel a commitment to the craft essential for maintaining an adequate supply of emergent leaders. But that positive resolve and zeal comes with a dark side: consumption. "Bunhead" is the colloquial term that refers to a female dancer whose life is consumed by ballet; many dancers identify themselves as bunheads. When not in class, rehearsing, or performing, they watch ballet videos, sew their pointe shoes, or simply practice more. Ballet leaders don't see the dangers in this level of dedication. Asked about others' perceptions of her, one artistic director stated, "They think I have no life outside of ballet, that I live, eat, and breathe ballet. They say I basically sleep here" (GA1). It is not uncommon for executive administrators to work seven days a week, for 14 weeks without a break during production season. One dancer who did recognize the dark side of dedication stated, "I started [dancing] later in life so my life doesn't revolve around ballet. I am lucky to be part of this world, but I am excited to go back to other worlds" (GD4). Even this statement, reveals her current level of dedication is unsustainable. 


\section{Communication}

Communicating on multiple levels is fundamental to ballet culture. Dancers use their bodies to convey meaning, emotions, attitudes and values. Whether a variation (solo dancer) or a pas de deux (partner dance), dancers tug at the heart strings and connect with the minds' eye through their virtuoso. Behind the scenes, choreographers and artistic staff are the puppet masters crafting the message to be communicated through steps and movement. Feedback during rehearsal, reminding dancers to "Express yourself," "Communicate," or "Perform," admonish them to breathe life into their work. This ability to communicate with an audience is what helps separate dancers from other athletes. But it is up to the artistic staff to communicate a vision and elicit from each individual exactly what is needed to bring that vision to life.

Production leaders, too, are an integral part of communicating that vision to audiences through costumes, lighting, and sets. On the executive side, the challenges of communication include reaching new and broader markets while sustaining relations with long time benefactors. Leaders in the ballet industry exploit the light dimension of communication, i.e. dialogue, to coordinate the multiple forms of creativity required to produce their artistry: Choreographers and artistic directors use dialogue to breathe life into the movements of dancers' bodies, creating storylines that communicate with audiences across language, class and ethnicity. Dialogue closes the distance between people within the organization, breaking down barriers between departments and resistance to ideas.

Yet, when communication ceases to be dialogue in these organizations, the darker dimensions of command and directive surface. Dancers often experience this dark dimension first hand, as every moment of their day and every step on the stage is dictated by someone else. Dancers routinely admit they are "to be seen and not heard," while in rehearsal or class, instructors simply dole out directives and yell commands. One dancer characterized communication in ballet as "obedience: "you have to take it a lot" (EC4). But it is not only with dancers that artistic directors and staff employ these dark dimensions of communication; wherever they are, their voice becomes the sole voice. Even when they are leading a meeting and others are expressing ideas, in the end theirs is the only voice that matters. Executive administrators, too, tend to use directives when communicating with artistic staff, so their exchange of messages falls short of being dialogue.

\section{Attention to Detail}

Another behavior valued among leaders in the ballet culture is attention to detail, with some admitting, "I can get hung up on the small things" (UA2). An entire artistic staff can spend hours finetuning the details of a new production to add layers of meaning to a performance, even if most viewers fail to take note on a conscious level. Similarly, the mantra in lighting is "attention to detail makes the magic". This extreme attention to detail is also what helps a dancer progress through constant fine-tuning. Administrators attend to fiscal and marketing details that impact the entire organization. As one chief operating officer commented, "You have to know the details of what you are trying to sell" (UE3); another cautioned that without attention to detail, "you will have blinders on" (UE10).

Leaders throughout the ballet industry excel at attention to detail; without it, they would be unable to orchestrate large scale productions with many moving parts. For example, costumers may search through mountains of fabrics to find the perfect jacquard or pass on a pink tulle that is too bubblegum-hued instead of carnation. These details are crucial, but they can become an obsession. This is the dark side of attention to detail: we "dwell on the small stuff" (EC1). An obsession with detail can earn an artistic director the label "micromanager" if she begins to dictate every facet or decision. When attention to detail

becomes a fixation, leaders can lose sight of the objectives or goal; there are indicators of these concerns in the ballet industry. Obsessive attention to detail in one part of the organization thwarts progress elsewhere, delaying production of new works, and raising concern the industry lacks long-term vision or forethought. 


\section{Individuality}

Individuality is woven throughout ballet culture; it is expected of leaders at every level. Individuality enables a dancer to stand out, not stick out, helping him or her rise through the ranks (UP1). Choreographers literally put their spin on every step and movement in a performance. Similarly, artistic directors re-envision timeless classics to reflect their unique perspectives. The individuality of other artistic staff is evident in the ways they insure against stagnation. Each individual dancer must hold her own amidst the other dancers in order for the entire formation to achieve coherence. But a principal dancer exhibits the ultimate individuality, commanding a stage all alone and infusing his or her own identity into a role (UP1).

Individuality in the ballet industry is distinct from independence; it is about standing out from the crowd, being distinguishable from others. The light side of individuality in ballet culture embraces diversity, allowing each dancer's, artistic director's or executive's uniqueness to be validated. Yet, there is evidence the pendulum of individuality sometimes swings too far among industry leaders, revealing a dark dimension, selfishness. Selfishness occurs when dancers choose to get ahead by diminishing, or "stepping on" others, or when a principal dancer hordes knowledge of technique to prevent others from advancing. Artistic directors typically achieve leadership roles by virtue of their individuality as dancers, but they can find it difficult to step out of the spotlight and remember that leading an organization is about collaborating toward a collective effort. Artistic directors often feel they are the personal brand, "the face", of the company, and they make the organization all about them. As one Artistic Director stated, "I am the business" (GA1). This is the dark manifestation of individuality in ballet leadership.

\section{Longevity}

Ballet culture does not want its leadership to be a revolving door, so longevity helps solidify placement of leaders in the industry. To prove themselves, individuals must demonstrate they can withstand the "trial by fire" required to achieve fidelity to ballet's ideals (EC7). Time in the industry affords individuals who "have paid their dues" experience in multiple roles and specialized knowledge, including "tricks of the trade" that contribute to leader effectiveness (EC9). Longevity helps a person know the ballet industry and a particular organization, so "they become what they know: they become the culture of the company" (GA2).

Leaders who achieve longevity in the ballet industry, or a specific company, are valued for providing prospective, history, and understanding of culture and tradition. Knowing where an organization or industry has been helps leaders understand where it can go, what can be changed, and how to grow. Yet the dark dimension of longevity, i.e. complacency, was observed to seep into these organizations. Artistic staff often mention this when speaking about executive administrators: "they think good is good enough" (GA1). Dancers think longevity breeds smugness, especially among those advanced in rank. Having reached the top, these leaders are perceived to "settle in", and in the opinions of those lower in the hierarchy, not work as hard or receive as much feedback: they take their leadership roles for granted.

\section{Appreciation}

An appreciation for the art form is the only way to survive, and thrive, in the ballet industry, and that appreciation is often what fuels the passion required for dedication to the profession. No dancer would endure the toll ballet takes on the body without an appreciation that many trace to childhood and claim can never be extinguished. This intrinsic appreciation is why most who are in it cannot fathom a different profession and never leave; they simply assume new roles (GA2). For those who transition into administrative roles, appreciation for the profession is similarly essential for sustaining their dedicated work ethic (GE3). Many executive administrators hold degrees that would permit more lucrative careers, but admit an appreciation for ballet propelled them into the industry. Nevertheless, one executive administer confessed, "I admire the passion and the drive, but it can be difficult to manage" (GE3).

While appreciation or love of the art form is considered essential for survival in the ballet industry, the dark dimension of appreciation can manifest as bias or partiality that causes leaders to develop "blinders" to the truth about the industry. Leaders who turn a blind eye to factors that give rise to eating 
disorders, the prevalence of abusive instructors, and the frequency of injured dancing, can start to see these things as 'normal' and are unable to remedy them. Because they are not as biased about ballet, executive administrators who have worked outside the industry sometimes conflict with insiders. These leaders see the beauty of ballet, but also see something dark lurking beneath it. A leader must be able to see both sides: "A lot of my complexes come from ballet, but so do my strengths of character" (EC3). When asked to describe experiences of the ballet industry as positive or negative, one dancer who had entered ballet at a young age as a form of physical therapy to correct internally rotated feet stated, "I don't know who I would have been without ballet. I cannot extrapolate it out: it is who I am" (EC7). That same dancer went on to relate horrific stories about body image dysmorphia and injury, yet her appreciation and love of ballet prevented her from rejecting these latter experiences as unacceptable. Other dancers with a little more objectivity put it differently: "With every pro, there is a con. You have to be a little crazy to take this on as a career" (EC5), or "I love ballet; it is a beautiful art form, but the values for females have rubbed me the wrong way" (EC3). One executive staff member, a former dancer, summarize her experiences with the industry this way:

I have struggled with a lot of things for a very long time. The tears coming to my eyes should be a sign of something. The negatives are right there, but I am pretty torn. It depends really on what I am looking at. I have been successful to a degree so it has to be a good match in some ways. Yet, these self-conscious aspects, the continued struggle to be secure, stay with you a long time and filter into other aspects of your life. (EE2).

This comment reflects both dimensions of appreciation: a love of ballet that can be blinding.

\section{Competition}

A competitive attitude is fostered by ballet culture and prevalent among those selected for leadership roles. With aspirations for bigger and better, dancers rise through the ranks by their competitive nature. At the barre, they stand beside their competition every day, vying for attention, critical feedback, rank and roles. Competition is what motivates dancers to push through pain and injury, and keep looking for advantage, lest they be replaced by a peer. Professional dancers know their competitive nature is what enabled them to secure placement in a company, when countless others wanted that spot. Artistic administrators compete not just with other companies but with themselves, as they strive to surpass previous seasons with more challenging choreography, elaborate costumes and impressive sets. Directors strive to beat last season's sales and to expand marketing and fundraising. Their competitive nature keeps leaders in the ballet industry on their proverbial toes, permitting them to outperform the competition.

Healthy competition can produce light effects in the ballet industry, but a dark dimension is evident that manifests as hostile aggression. The light side of competition creates teamwork, increases productivity, and fosters motivation and creativity among members striving to improve or outperform their neighbor. But the dark dimension of competition can transform healthy rivalry into sabotage, either mental or physical or both. Dancers are aware that others secretly hope they become injured, so others may assume their position. The dark dimension of competition can render the casting environment so hostile that dancers lose the ability to separate professional from personal: "they think that an artistic director has a personal vendetta against them" (EC1). This transition from competition to hostile aggression can also occur between executive and artistic staff who may try to outperform each other, speaking ill of the other, or attempting to sabotage their success. The distinction between the light and dark dimensions of competition are evident to everyone in the industry, although nobody wants to accept fault.

\section{Fearlessness}

Coupled with competition is a fearless attitude that fuels a willingness to take risks. Dancers are often told to "go for it" when attempting new steps, especially those involving lifts during which a ballerina fearlessly trust her partner. Fear causes the body to stiffen, ensuring the lift will fail and gracefulness will 
be lost. But dancers sometimes exhibit a reckless degree of fearlessness when they continue dancing with an injury, and fearlessness is what keeps dancers dancing for paltry salaries, with no retirement or job security. Because dancers consider the stage "a temple, a scared space" (UP1), their fears are secondary. For executive leaders, fearlessness is required in the face of constant financial challenges, while the artistic staff fearlessly push the boundaries of artistry in pursuit of the ideal. Failure cannot be an option because the performance must occur at all costs.

Fearlessness allows leaders in the ballet industry to make decisions when others are unable to do so. The light dimension of fearlessness permits dancers to attempt new steps, choreographers to introduce new sequences, production staff to construct new sets or costumes, and executives to create new marketing strategies. But the dark dimension of fearlessness manifests as recklessness. Both light and dark manifestations of fearlessness involve risk-taking, but the former is calculated while the latter is not. It is necessary for dancers to take calculated risks in order to develop and succeed. But when the potential consequences of a new venture or decision are not considered, or are miscalculated because of cloudy judgment, forging ahead can be reckless. The longer a dancer's career, the riskier dance becomes, because with age come limitations that are sometimes not accepted. Continuing to dance without recalibrating risk can become reckless, endangering health and career. Artistic directors who try to circumvent company policies, and administrators who fail to consult with others when planning events, similarly flirt with the dark side of fearlessness.

\section{Confidence}

Confidence is essential for success at the professional level in the ballet industry, so it is not surprising this attribute is valued among its leaders. When a dancer admits not having the feet or body of a prototypical dancer, confidence is what keeps him or her dancing. Confidence keeps self-doubt at bay in the face of constant criticism, injury or being passed over for coveted parts. Enduring failure and adversity actually helps build dancers' confidence, convincing them they are worthy to perform this art form. It is this ethereal 'armor' of confidence dancers carry with them into leadership roles that enables them to provide vision, instruction and direction for making the ideals in their heads seem attainable. Without confidence, artistic leaders could not provide the necessary feedback to groom younger dancers. Non-dancers selected for executive leadership positions in the ballet industry, must be confident their abilities will transfer, that they can learn the industry, and will be successful raising funds and marketing a product that is in many ways outside the mainstream of American culture.

Although confidence among members of the ballet industry allows leaders to command a room or stage, its dark dimensionality can reflect narcissistic or arrogant behavior. A dancer's preoccupation with the mirror is just one example of this obsessive self-absorption. One dancer admits, "We [dancers] value ourselves" (UC1), and this can create an exaggerated desire for attention. Reflecting their insecurities, dancers vie for the small amount of praise provided by leaders in the ballet industry, becoming preoccupied with catching the eye of the artistic director. But this dark dimension of confidence can interfere with advancement, as one artistic director noted, "Some people don't want to be teachable. Ego is their defense: they are afraid to try" (GA1). Artistic staff, too, benefit when they exude confidence in their roles, but that can easily become "ego" (EE2) or "hubris" (GE1) masking the same underlying insecurities. The contrast between light and dark dimensions is obvious: One dancer observed about a confident leader, "They make it work for everybody, including themselves" (EC1), while an egotistical leader, "Thinks only about yourself and nothing else; it needs to be about the group (GD11), and a narcissistic leader is only about, "What's it in for them?" (GD13). Executive administrators also decry this duality of confidence among the artistic staff; as one commented, only an arrogant leader, "would go in the wrong direction and justify it; when you eat what you kill it effects everyone" (GE1). These examples reflect the insidious nature of the dark side of confidence. A dancer or artistic director may think he or she is exhibiting confidence, while others see arrogance. One dancer with insight into this duality observed, "Arrogance gets in the way; you have to let go of pride, otherwise when you try something new it will be ugly" (GD10). 


\section{CONCLUSIONS}

Evidence from this ethnographic study presented above support the following conclusions relative to stated research questions:

\section{Culturally-determined Prototypically}

With respect to prototypically, the findings of this study provide evidence consistent with predictions based on social identity theory (Hogg, 2001), which asserts organizational culture plays a causal role in determining what attributes are prototypical of members in specific organizational contexts (RQ1), and prototypically predicts leader emergence (RQ2). These findings are also consistent with Zaccaro's (2007) trait-based theory of leadership which prescribes a moderating effect of a leader's operating environment on leader emergence. While the ethnographic nature of the evidence reported precludes conclusions regarding causality, that the reported qualitative results of this study are consistent with these theoretical predictions is a significant finding. These results provide preliminary support for the theoretical framework which predicts organizational culture has a direct role in determining what attributes are prototypical of organization members, and an indirect role in determining which individuals emerge as leaders in those organizations, based on their prototypically (see Figure 1).

\section{Attribute Dimensionality}

With respect to attribute dimensionality, the findings of this study provide evidence consistent with predictions derived from Judge et al.'s (2009) trait-based theory of leadership that leaders embody both "light" and "dark" dimensions of attributes prototypical of their organizational culture (RQ3). Like other members of these organizations, leaders in the ballet industry, simultaneously exhibited behaviors, attitudes and decisions consistent with the culturally-determined "light" and "dark" manifestations of prototypical attributes, reflecting both favorable and unfavorable implications for their followers and the organizations they serve. These results provide preliminary evidence extending Hogg's (2001) social identity theory to include the influence of culture in determining the dimensionality of prototypical attributes in organizational contexts.

\section{Moderation of Dimensionality}

Finally, with respect to leader prototypically, there is little evidence from this study to suggest that individuals who emerge as leaders moderate the degree to which they embody the "light" and "dark" dimensions of prototypical attributes relative to other members of the organization (RQ4). Leaders were found to be just as likely as other members of these organizations to adopt behaviors, attitudes and decisions that reflect the "dark" dimensions of prototypical attributes, and no more likely to behave in ways consistent with the "light" dimensions. This suggests that leaders are not individuals uniquely skilled at navigating between the light and dark extremes of prototypical attributes, such that they embody the light manifestations, while managing to keep the dark dimensions in check. On the basis of these result we reject the idea that leaders are more self-regulated than other organization members with respect to moderating the expression of dimensionality in the culturally-determined prototypical attributes they embody.

\section{DISCUSSION}

The ethnographic evidence from this study of the ABI suggests leaders are prototypical of an organization's culture with respect to both the "light" and "dark" dimensions of leadership attributes they manifest. Results reinforce Hogg's (2001) social identity theory of leadership and have implications for understanding the moderating effects of organizational culture on leader emergence and effectiveness (Zaccaro, 2007). Support was found for the role organizational culture is theorized to play in shaping the light and dark dimensions of attributes that emerge as prototypical of organizational members, and those elevated to leadership roles (Judge et al., 2009). While previous survey research documented the 
influence of national culture on leaders' character traits (Judge, 2001) and "dark" personality characteristics (Gaddis and Foster, 2015), our results offer empirical evidence that organizational culture operates within specific industries to determine both what attributes are prototypical, and their light and dark dimensionality.

Employing ethnographic methods to extract leader attributes, rather than imposing a pre-existing taxonomy of light and dark dimensions, resulted in a more extensive, specific and meaningful set of attributes for understanding the prototypical attributes that contribute to leader emergence in the ballet industry, and the light and dark dimensions of those attributes that manifest among individuals elevated to leadership positions. While some of the attributes identified as prototypical of the ballet culture can be found in other character-based taxonomies (Peterson and Seligman, 2004), there is little conceptual overlap with the Big Five personality characteristics (Costa and McCrae, 1992). Only 4 of the 14 prototypical attributes extracted from this study overlap conceptually with the 27 character strengths cataloged by Peterson and Seligman (2004): independence, dedication ("persistence"), fearlessness ("bravery"), and artistry ("appreciation of beauty and excellence") (p. ix-xi). When considering the "dark" dimensions of prototypical leader attributes in ballet culture, however, our analysis found far more conceptual overlap with the Hogan assessment scale, discovering 7 of the 11 "dark" attributes represented: artistry ("imaginative"), competition ("skeptical"), confident ("bold"), fearless ("mischievous"), individuality ("colorful"), longevity ("leisurely"), perfectionism ("diligent") (Hogan and Hogan, 2001, p. 42). With respect to the theoretical question of dimensionality, these results provide strong ethnographic evidence that prototypical individuals elevated to leadership positions within the ballet industry reflect both light and dark dimensions of desirable attributions, and point to the methodological advantages of ethnographic approaches to understanding the light and dark dimensions of leadership in organizational contexts.

\section{Implications and Future Research}

When considering the implications of this study for theory and practice, it is important to acknowledge the ethnographic nature of evidence reported, and the fact that data were collected from only three regional ballet companies in the United States. Caution must be exercised in extrapolating results to the entire ABI, or other organizations. Nevertheless, data collected provide a foundation for conducting more comprehensive industry-wide assessments using other epistemological approaches that extend the external validity of these findings.

With respect to future research opportunities, methodologies employed in this study lay the groundwork for conducting similar studies in other organizations and industry groups to confirm how widely these conclusions extrapolate. This study identified a broader range of prototypical leadership attributes characteristic of the ballet industry than is currently represented in scaled assessment instruments designed for conducting normative studies of the dark side of leadership. Leadership attributes extracted from our analysis, together with their "light" and "dark" dimensions, provide a taxonomy for developing survey instruments that could provide a basis for more exhaustive, quantitative assessments of attribute dimensionality, extending results to other organizational contexts and industries. There may also be utility in operationalizing these attributes so their prevalence in other types of organizations can be systematically documented.

Beyond specific research questions addressing the prototypically of leader emergence in the ballet industry, this study sheds light on the broader theoretical framework proposed by Padilla, Hogan, and Kaiser (2007) for understanding the interplay of "dark" attributes among leaders and followers in the cultural context of individual organizations. Our data suggest ballet culture embodies all three components these scholars theorize constitutes the "toxic triangle" of destructive leadership: "destructive leaders", "susceptible followers" and "conducive environments" (p. 180). According to their model, destructive leadership is comprised of a nexus of factors jointly constituted by leaders, followers and the culture of the organization. Results of our ethnographic analysis provided evidence that 7 of the 11 dark dimensions that constitute the leadership dimension of this toxic triangle are present in the ABI. To the extent followers in these organizations reflect the "dark" attributes prototypical of the industry we would 
expect they represent the "colluders" and "conformers" that comprise the vulnerable followers described in Padilla et al.'s (2007) model.

The cultural profile that emerged from this study reflects evidence of the instability, perceived threats, and lack of checks and balances that render organizations conducive to destructive leadership (Padilla $e t$ al., 2007). Together, this evidence suggests these organizations represent prime targets for conducting theory-driven research in the future, aimed at assessing all three dimensions of the toxic triangle simultaneously. Given our results also found leaders to be no more adept at moderating their behavior to reflect more "light" and less "dark" dimensionality than other organization members affords some urgency to advancing this research agenda.

\section{REFERENCES}

Alasuutari, P. (1995). Researching Culture: Qualitative Method and Cultural Studies. Sage, London. Benson, M.J., \& Campbell, J.P. (2007). To be, or not to be, linear: An expanded representation of personality. International Journal of Selection and Assessment, 15, 232-249.

Costa, P.P., \& McCrae, R.R. (1992). Revised NEO Personality Inventory. Psychological Assessment Resources, Odessa, FL.

Driskell, G.W., \& Brenton, A.L. (2011). Organizational Culture in Action, Sage, London.

Fetterman, D.M. (1998). Ethnography, $2^{\text {nd }}$ ed. Sage, Thousand Oaks, CA.

Furnham, A., \& Crump, J. (2014). A Big five facet analysis of sub-clinical narcissism. Personality and Mental Health, 8, 209-217.

Furnham, A., Hyde, G., \& Trickey, G. (2014). Do your dark side traits fit? Applied Psychology: An International Review, 63, 589-606.

Gaddis, B.H., \& Foster, F.L. (2015). Meta-analysis of dark side personality characteristics and critical work behaviors. Applied Psychology: An International Review, 64, 25-54.

Harms, P.D., Spain, S.M., \& Hannah, S.T. (2011). Leader development and the dark side of personality. Leadership Quarterly, 22, 495-509.

Hogan, R. (2016). Reflections on the dark side. Talent Quarterly, 8, 1-4.

Hogan, R., \& Hogan, J. (2001). Assessing leadership: A view from the dark side. International Journal of Selection and Assessment, 9, 12-23.

Hogg, M.A. (2001). A social identity theory of leadership. Personality and Social Psychology Review, 5, 184-200.

Holton, J.A. (2007). The coding process and its challenges. Brant, A and Charmaz, K., The Sage Handbook of Grounded Theory. Sage, Los Angeles, pp. 265-289.

Judge, W.Q. (2001). Is a leader's character culture-based or culture-free? Journal of Leadership \& Organizational Journal, 8, 63-78.

Judge, T.A., Piccolo, R.F., \& Kosalka, T. (2009). The bright and dark sides of leader traits. Leadership Quarterly, 20, 855-875.

Kaiser, R.B., LeBreton, J.M., \& Hogan, J. (2015). The dark side of personality and extreme leader behavior. Applied Psychology: An International Review, 64, 55-92.

Kelly, D. (2012). Ballerina: Sex, scandal, and suffering. Greystone Books, Vancouver, Canada.

Khoo, H.S., \& Burch, G.S.J. (2008). The 'dark side' of leadership personality and transformational leadership. Personality and Individuality Differences, 44, 86-97.

Louis, M.R. (1990). Acculturation in the workplace", Schneider, B. Organizational Climate and Culture. Jossey-Bass, San Francisco, pp. 85-129.

McCrae, R.R., \& Costa, P.T. (1987). Validation of the 5-factor model of personality across instruments and observers. Journal of Personality and Social Psychology, 52, 81-90.

Padilla, A., Hogan, R., \& Kaiser, R.B. (2007). The toxic triangle: Destructive leaders, susceptible followers, and conducive environments. Leadership Quarterly, 18, 176-194.

Peterson, C., \& Seligman, M.E.P. (2004). Character Strengths and Virtues, Oxford University. Schultz, M. (1995). On Studying Organizational Cultures. Walter de Gruyter, New York. 
Simonet, D.V, Tett, R.P, Foster, J, Angelback, A.I., \& Bartlett, J.M. (2018). Dark-side personality trait interactions. Journal of Leadership \& Organizational Studies, 25, 233-250.

Whitley, B.E., \& Kite, M.E. (2013). Principles of Research in Behavioral Science. Routledge, London. Zaccaro, S.J. (2007). Trait-based perspectives of leadership. American Psychologist, 62, 6-16.

Zaccaro, S.J., Kemp, C., \& Bader, P. (2004). Leader traits and attributes, Antonakis, J., Cianciolo, A.T and Sternberg, R.J., The Nature of Leadership. Sage. London, pp. 101-124.

Zibarras, L., Prot, R., \& Woods, S. (2008), "Innovation and the "dark side" of personality. Journal of Creative Behavior, 42, 201-21. 